\title{
Editorial
}

\section{La investigación como motor de crecimiento en las Ciencias del Deporte}

\author{
Jesús Fernández Gavira \\ Jerónimo García Fernández
}

El aumento del interés por la práctica deportiva, las necesidades del mercado laboral, el incremento del número de empleados en la industria del deporte, la introducción de la tecnología como herramienta para la mejora y la promoción del deporte, así como la percepción por parte de la Administración a regular las profesiones del deporte, está influyendo en que las Ciencias del Deporte se estén consolidando a través de la investigación y la creación de conocimiento (Márcia, Soler, Puig y Prat, 2014).

Si bien el deporte, como actividad, se viene practicando durante gran parte de nuestra historia moderna, las Ciencias del Deporte no se han considerado como una disciplina de larga tradición académica hasta el siglo XX. En particular, Borms (2008) las define como sistema de la investigación científica, enseñanza y práctica que integra el conocimiento de otras disciplinas. El propósito y función de las Ciencias del Deporte es investigar cuestiones, las cuales han de resolverse con una base científica. Finalmente, las soluciones tienen que ser aplicadas para explicar, controlar, y si es necesario, cambiar la práctica deportiva. Las Ciencias del Deporte son principalmente visibles a través de su cuerpo de conocimiento que es el resultado del esfuerzo científico en relación al deporte" (p. 10).

Por su parte el International Council of Sport Science and Physical Education (ICSSPE) propone 18 disciplinas académicas en las Ciencias del Deporte: biomecánica del deporte, medicina del deporte, fisiología del deporte, psicología del deporte, historia del deporte, pedagogía del deporte, filosofía del deporte, sociología del deporte, actividad física adaptada, equipamiento e instalaciones deportivas, kinantropometría, educación física, entrenamiento deportivo, comportamiento motor, economía del deporte, legislación deportiva, gestión deportiva y administración deportiva (Talbot, Haag y Keskinen, 2013). Dichas disciplinas están fomentando una creciente investigación, que no solo tiene una gran transcendencia en la sociedad, sino que está fomentando una ciencia que aporta valor al campo científico y genera conocimiento.

Así, este número especial dedicado a la investigación como motor de crecimiento en las Ciencias del Deporte, está conformado por siete artículos. En el primero, Moisés Contreras de la Osa y Jorge Abellán, examinan el efecto de una unidad didáctica de deporte adaptado sobre las actitudes hacia la discapacidad en Educación Física y sobre la competencia social y cívica de estudiantes de Educación Primaria, a través de la utilización del modelo de enseñanza comprensiva de los deportes. Los hallazgos encontrados por estos autores implican que la inclusión del deporte adaptado en Educación Física en Primaria es aconsejable, especialmente en lo relacionado con la mejora de la competencia social y cívica. 
El segundo trabajo realizado por Manel Valcarce, muestra el protocolo de un estudio cuyos objetivos principales son conocer la influencia de una app móvil sobre la adherencia a la práctica deportiva de usuarios de centros deportivos, así como al propio centro. El tercer artículo, presenta la transferencia de beneficios para la valoración de los impactos de bienes púbicos asociados a eventos o infraestructuras deportivas, y que es necesaria para poder realizar el ACB. Joan Mogas plantea su estudio como una alternativa respecto a hacer una nueva investigación que implica tiempo y dinero, permitiendo así acelerar la toma de decisiones en la política deportiva.

En el cuarto artículo, Víctor Marín De La Fuente y colaboradores analizan el autoconcepto, el rendimiento académico y la práctica deportiva extraescolar de los alumnos, con la intención de comprobar si el hecho de realizar práctica extraescolar o no, supone cambios en los niveles de autoconcepto y rendimiento académico, así como comprobar si existe significación en la relación entre el autoconcepto de los alumnos y su rendimiento académico. El número especial sigue con el artículo de Isabel Acero, el cual analiza los distintos factores que influyen en mayor medida a la hora de determinar el rendimiento individual de un ciclista en la Vuelta Ciclista España. Sus resultados muestran que tanto el peso del ciclista como la experiencia y calidad del mismo son factores importantes, así como la especialidad del corredor. Por su parte, Fernando Mata-Ordóñez y colaboradores, realizan una revisión teórica buscando esclarecer los factores que afectan al sueño, los efectos de éste sobre el rendimiento deportivo y la salud, así como explicar las estrategias más determinantes para mejorar la cantidad y calidad del sueño del deportista. Diferentes estrategias como la extensión del sueño, las siestas, estrategias de higiene del sueño y nutricionales deben ser consideradas en la mejora del sueño del deportista se muestran como resultados de su trabajo. Finalmente, Sánchez-Oliver realiza una revisión para analizar qué estudios existen sobre los efectos de la suplementación deportiva en jugadores/as de fútbol sénior de nivel profesional.

En definitiva, un número en el que se dan cita investigadores de diferentes disciplinas de las Ciencias del Deporte con el que esperamos que el lector disfrute.

\author{
Dr. Jesús Fernández Gavira \\ Dr. Jerónimo García Fernández \\ Universidad de Sevilla \\ jesusfgavira@us.es \\ jeronimo@us.es
}

\title{
REFERENCIAS BIBLIOGRÁFICAS
}

Borms, J. (2008). Directory of Sport Science. Berlin: Human Kinetics.

Márcia, A., Soler, S., Puig, N., y Prat, M. (2014). El proceso Bolonia y sus efectos en el campo de las Ciencias de la Actividad Física y del Deporte en España. Movimento, 20(3), 1061-1082.

Talbot, M., Haag, H., y Keskinen, K. (2013). Directory of sport science (6ª Ed.). Berlín: Human Kinetics. 